\title{
Affective processing within 1/10th of a second: High arousal is necessary for early facilitative processing of negative but not positive words
}

\author{
Markus J. Hofmann, Lars Kuchinke, and Sascha Tamm \\ Free University Berlin, Berlin, Germany \\ Melissa L.-H.Võ \\ University of Edinburgh, Edinburgh, Scotland \\ AND \\ ARThur M. JACOBS \\ Free University Berlin, Berlin, Germany
}

\begin{abstract}
Lexical decisions to high- and low-arousal negative words and to low-arousal neutral and positive words were examined in an event-related potentials (ERP) study. Reaction times to positive and high-arousal negative words were shorter than those to neutral (low-arousal) words, whereas those to low-arousal negative words were longer. A similar pattern was observed in an early time window of the ERP response: Both positive and high-arousal negative words elicited greater negative potentials in a time frame of 80 to $120 \mathrm{msec}$ after stimulus onset. This result suggests that arousal has a differential impact on early lexical processing of positive and negative words. Source localization in the relevant time frame revealed that the arousal effect in negative words is likely to be localized in a left occipito-temporal region including the middle temporal and fusiform gyri. The ERP arousal effect appears to result from early lexico-semantic processing in high-arousal negative words.
\end{abstract}

From an evolutionary perspective, deciding appropriately on emotionally significant stimuli is an essential ability that aids survival. Reacting fast to positive stimuli maximizes the probability of attaining an appetitive state. In contrast with this "first come, first served" principle, two complementary response tendencies can be observed for negative stimuli. Negative arousing stimuli, such as "earthquake" or "alarm," are best dealt with by initiating a fast response. In contrast with this "fight or flight" mechanism, "freezing" can be utilized, for example, to help prey to escape undetected. LeDoux (1996) suggested that ready-made neural pathways of evolutionarily old mechanisms can be activated by newly developed capabilities. Thus, it may be advantageous to respond quickly to symbolic stimuli, such as words, if they signal appetitive or potentially threatening situations. To address this issue, the present study used emotional words in the lexical decision task in which speeded responses were required to decide whether a presented letter string was a word or not.

For words with a negative affective connotation, rather inconsistent behavioral results have been obtained. Some previous studies have shown that subjects reacted faster to negative than to neutral words (Williamson, Harpur, \& Hare, 1991; Nakic, Smith, Busis, Vythilingam, \& Blair, 2006). In contrast, most studies have shown no difference
(Siegle, Ingram, \& Matt, 2002), or even a trend toward slower reaction times (RTs; Kuchinke et al., 2005; Larsen, Mercer, Balota, \& Strube, 2008; MacKay et al., 2004). An approach that is as old as psychology itself may account for this divergence in negative emotion words. Following Wundt's (1896) suggestion, emotion is now commonly subdivided into at least two orthogonal dimensions that constitute the affective space: valence and arousal (Bradley \& Lang, 1999; Osgood, Suci, \& Tannenbaum, 1957). In the present article, we tested the prediction that high-arousal negative words decrease RTs (Hackley \& Valle-Inclán, 1999); we expected no effect or even an RT increase for negative words that were matched for arousal to neutral words (Larsen et al., 2008; Siegle et al., 2002).

The German corpus used for stimulus selection revealed a differential arousal distribution for positive and negative words (see Figure 1 in Võ et al., 2009). Therefore, it was impossible to generate high- and low-arousal positive and negative conditions that would have been matched for arousal, particularly while controlling for the most influential variables in word recognition (Graf, Nagler, \& Jacobs, 2005). Since positive words consistently decreased lexical decision times (Kuchinke et al., 2005; Kuchinke, Võ, Hofmann, \& Jacobs, 2007; Williamson et al., 1991), we tested whether the effect of positive words was due to 


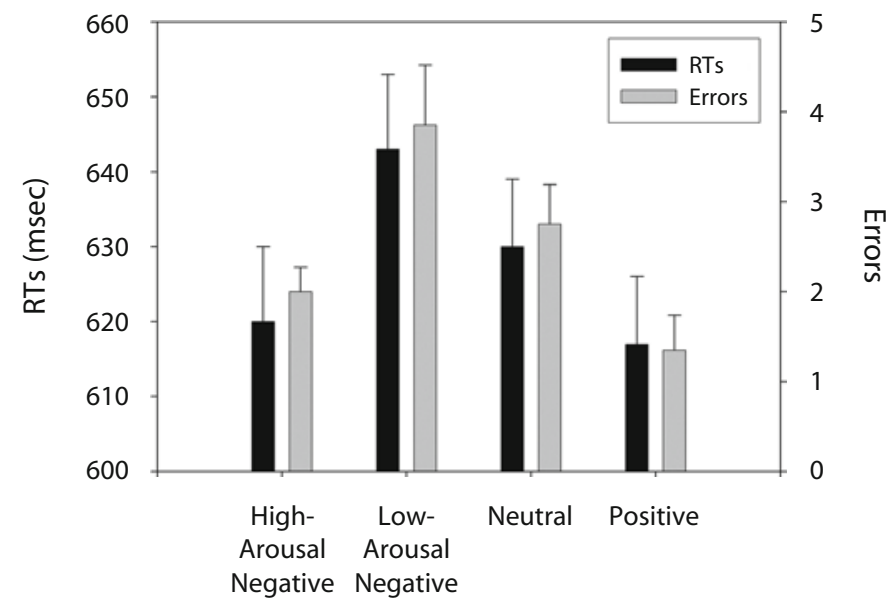

Figure 1. Mean reaction times (RTs) and errors for the four stimulus conditions $(N=20)$. Error bars indicate standard errors.

positive emotional valence independent of arousal. For this purpose, we used a condition of low-arousal positive words. For negative words, in contrast, we tested whether the inconsistent behavioral findings of previous studies can be attributed to arousal by comparing high- and lowarousal negative conditions.

This resulted in four stimulus categories that were matched for various potentially confounding variables $\left(F_{\mathrm{S}}<1\right.$; see Table 1$)$. Positive, neutral, and low-arousal negative words were matched for their arousal level. High-arousal negative words were matched with respect to valence to the low-arousal negative words, but were maximized with respect to arousal (see Table 1; for further details, see the Method section).

In addition to testing whether the behavioral facilitation for positive words occurs when arousal is controlled for, and whether arousal modulates the behavioral facilitation in negative words, we targeted the time frame of the processes responsible for the behavioral facilitation.
This issue also concerns the interpretation of affective effects as being of lexical or postlexical origin. Sereno and Rayner (2003) proposed that lexical access is underway already around $100 \mathrm{msec}$ after stimulus presentation (see also Dambacher, Kliegl, Hofmann, \& Jacobs, 2006; Hinojosa, Martín-Loeches, \& Rubia, 2001; and Sereno \& Rayner, 2003, for reviews). However, Kissler, Herbert, Peyk, and Junghofer (2007) found ERP correlates of emotional word processing not before $200 \mathrm{msec}$, and concluded that emotional processing occurs after lexical access (cf. Herbert, Junghofer, \& Kissler, 2008). Kissler et al. (2007) used a rapid serial visual presentation paradigm in which no decision was required after word presentation. However, if affective information processing provides an evolutionary advantage because it allows for making faster decisions, tasks requiring speeded decisions might produce different results. We thus used a lexical decision task in order to test whether emotional information is still processed after lexical access, even when a fast decision is required. Since

Table 1

Mean Values and Standard Errors of the Control and Manipulation Variables for the Four Stimulus Conditions

\begin{tabular}{|c|c|c|c|c|c|c|c|c|}
\hline \multirow{3}{*}{$\begin{array}{c}\text { Control and Manipulation } \\
\text { Variables }\end{array}$} & \multicolumn{8}{|c|}{ Stimulus Condition } \\
\hline & \multicolumn{2}{|c|}{$\begin{array}{l}\text { High-Arousal } \\
\text { Negative Words }\end{array}$} & \multicolumn{2}{|c|}{$\begin{array}{l}\text { Low-Arousal } \\
\text { Negative Words }\end{array}$} & \multicolumn{2}{|c|}{ Neutral Words } & \multicolumn{2}{|c|}{ Positive Words } \\
\hline & $M$ & $S E$ & $M$ & $S E$ & $M$ & $S E$ & $M$ & $S E$ \\
\hline Emotional valence & -1.61 & 0.04 & -1.57 & 0.04 & -0.04 & 0.03 & 1.55 & 0.05 \\
\hline Arousal & 3.94 & 0.04 & 3.15 & 0.04 & 3.08 & 0.06 & 3.16 & 0.09 \\
\hline Imageability & 4.22 & 0.18 & 4.00 & 0.19 & 4.23 & 0.20 & 4.23 & 0.17 \\
\hline Number of letters & 6.34 & 0.17 & 6.40 & 0.19 & 6.26 & 0.15 & 6.26 & 0.18 \\
\hline Number of syllables & 2.08 & 0.11 & 2.14 & 0.11 & 2.04 & 0.06 & 2.14 & 0.09 \\
\hline Word frequency & 7.00 & 1.25 & 5.97 & 1.56 & 6.72 & 1.45 & 7.94 & 1.37 \\
\hline Number of orthographic neighbors & 0.96 & 0.25 & 0.86 & 0.17 & 1.04 & 0.20 & 1.02 & 0.23 \\
\hline Mean letter frequency (type) & 32,108 & 959 & 31,975 & 706 & 31,770 & 1,178 & 31,062 & 1,088 \\
\hline Mean letter frequency (token) & $1,733,451$ & 70,562 & $1,708,311$ & 54,517 & $1,700,929$ & 81,118 & $1,665,834$ & 75,498 \\
\hline Mean bigram frequency (type) & 3,677 & 252 & 3,445 & 234 & 3,684 & 297 & 3,480 & 301 \\
\hline Mean bigram frequency (token) & 210,107 & 20,734 & 191,082 & 18,684 & 194,017 & 21,358 & 204,375 & 23,441 \\
\hline
\end{tabular}

Note-The ranges of the rating variables are: valence, -3 to +3 ; imageability, 1 to 7 ; and arousal, 1 to 5 . Word frequency is given as occurrence per 1 million words. Type measures denote the number of words in which the sublexical unit occurs in a lemma corpus of 51,207 words. Token measures indicate the summed word frequencies of these words. 
lexical access is assumed to be underway around $100 \mathrm{msec}$ after stimulus presentation (Sereno \& Rayner, 2003), and emotional processing has been found to affect the ERP time course from 80 to $120 \mathrm{msec}$ (Scott, O'Donnell, Leuthold, \& Sereno, 2009), the present study targeted this time frame. Scott et al.'s results already challenged Kissler et al.'s proposal of affective information acting after lexical access. This suggests the necessity of specifying conditions for the occurrence of lexical access effects. The participants in the present study were put under severe time pressure. According to the multiple read-out model of word recognition (MROM; Grainger \& Jacobs, 1996), speeded instructions put an emphasis on an early lexical fast-guess mechanism that might favor early affective effects.

To identify the most likely sources of early electrophysiological responses, we conducted sLORETA source localization. We expected the anterior cingulate to emerge as the most likely source, if attention processes were the most likely explanation for response facilitation effects. Carretié, Hinojosa, Martín-Loeches, Mercado, and Tapia (2004) indeed found that an ERP effect in the processing of affective pictures around $100 \mathrm{msec}$ was likely to be localized in the anterior cingulate cortex. Furthermore, Geday, Gjedde, Boldsen, and Kupersa (2003) suggested that the behavioral facilitation found with affective stimuli might result from attentional processes in the medial prefrontal cortex, including the anterior cingulate cortex.

Another region of interest to which LORETA appears to be sensitive is the fusiform gyrus. For example, Pizzagalli et al. (2002) found emotional faces to engage the fusiform gyrus (cf. Geday et al., 2003) in an early time frame starting at $120 \mathrm{msec}$ after stimulus presentation. For word processing, the fusiform gyrus was discussed to act at a visual word form level of processing (Dehaene, Le Clec'H, Poline, Le Bihan, \& Cohen, 2002), or to act as a hub between orthographic and semantic processing (Price \& Devlin, 2003). Support for the latter hypothesis would result from activation differences in the medial temporal gyrus, which was suggested to be involved in semantic processing (Price, 2000).

\section{METHOD}

\section{Participants}

Twenty native German participants took part in the experiment (16 female, mean age 28 years; 1 was left-handed). They were neurologically healthy and reported no language or speech impairments. Participants received course credits or were paid for their participation.

\section{Materials}

The stimulus set consisted of 200 words and 200 nonwords. Word stimuli consisted of 4- to 8-letter German nouns. We used four stimulus conditions, each comprising 50 stimuli. Positive (e.g., RUHM [fame]), neutral (e.g., BEFUND [finding]), and low-arousal negative words (e.g., APATHIE [apathy]) were matched for arousal. Higharousal negative words (e.g., ERDBEBEN [earthquake]; see Table 1) were matched with respect to valence to the low-arousal negative words, but were maximized with respect to arousal. To control for the undesired influences of other variables that are known to affect lexical decision performance (Graf et al., 2005), nine further vari- ables were matched (all $F \mathrm{~s}<1$; see Table 1). Estimates for emotional valence and imageability were taken from the Berlin Affective Word List in its revised form (BAWL-R; Võ et al., 2009). Emotional valence ratings ranged from -3 (very negative) to +3 (very positive), imageability ratings from 1 (low imageability) to 7 (high imageability), and arousal ratings from 1 (low arousal) to 5 (high arousal). Word frequency measures are given in occurrences per million (Baayen, Piepenbrock, \& Gulikers, 1995). Mean letter and bigram frequencies were taken from the lemma corpus of Hofmann, Stenneken, Conrad, and Jacobs (2007). Respectively 100 nonwords were generated by replacing the vowel of a nontarget word with either another vowel (e.g., ERREGER $\rightarrow$ ERREG $\underline{U}$ ) or a consonant (e.g., $\mathrm{MOKKA} \rightarrow \mathrm{MOKK} \underline{\mathrm{w}})$.

\section{Procedure}

Participants were seated on a comfortable chair in front of a 17-in. color monitor $(70 \mathrm{~Hz})$ in a dimly illuminated room. Distance from eye to monitor was about $70 \mathrm{~cm}$. The participants were instructed to respond as fast and as accurately as possible. Experimental stimuli were presented in two blocks, each comprising 200 stimuli. Both blocks contained an equal number of nonwords and words of each stimulus category, and did not differ in any of the control or manipulation variables (see Table $1 ; F_{\mathrm{S}}<1$ ). The participants were briefed to press the left index finger for words and the right index finger for nonwords in the first block. This assignment was reversed for the other block. The order of blocks was counterbalanced across participants. Each block was preceded by 10 practice stimuli.

Stimuli were presented in black uppercase letters (Times New Roman font, $20 \mathrm{pt}$ ) on a white screen by Presentation 9.0 software (Neurobehavioral Systems, Inc., Albany, Canada) in a pseudorandomized fashion. No more than three words or nonwords were allowed to appear consecutively. Each trial began with a fixation cross (+) presented for $700 \mathrm{msec}$, followed by the stimulus for $1,000 \mathrm{msec}$. Participants were instructed to respond before the stimulus offset. After a blank screen appeared for $500 \mathrm{msec}$, a mask (\#\#\#\#) was presented for $1,500 \mathrm{msec}$. Participants were instructed to blink only during the masking period.

\section{Data Acquisition}

EEG data were recorded by a 32-channel amplifier (Brainamp; Brain Products, Germany) using 28 electrodes attached to an elastic cap (EASYCAP, Germany). These were referenced to the right mastoid. Vertical EOG was recorded above and below the right eye, and the horizontal EOG on the outer canthus of each eye. Impedances for the EOG electrodes were kept below $10 \mathrm{k} \Omega$, and all other electrodes were kept below $5 \mathrm{k} \Omega$. EEG data were sampled at $250 \mathrm{~Hz}$. Pupil dilations were concurrently recorded using a videobased IView X Hi-Speed eyetracker (SensoMotoric Instruments, Germany). Pupillometric data were not the primary scope of the present article. Neither emotional valence nor arousal affected the pupillary response. These findings confirmed the results of a prior pupillometric study (Kuchinke et al., 2007), but are not uncontroversial (Võ et al., 2008).

\section{Data Analysis}

EEG data analysis was conducted using Brain Vision Analyzer software (Brain Products, Germany). Data were band-pass filtered (0.1-20 Hz). Muscle artifacts, drifts, amplifier blockings, and eye movements were rejected by visual inspection. Blink artifacts were corrected using independent component analysis (Onton, Westerfield, Townsend, \& Makeig, 2006). ERPs were corrected relative to a 200 -msec prestimulus baseline and were averaged per subject and condition. Reactions prior to $300 \mathrm{msec}$ were excluded from analyses. Reactions $1 \mathrm{sec}$ poststimulus were not recorded and were counted as errors. Behavioral errors were excluded from electrophysiological and RT analyses. More than 35 trials per subject and condition remained for analyses. In sum, $93 \%$ of the trials remained for the analyses of the electrophysiological data. 
In order to test for main effects of the stimulus conditions and their potential interactions with topography, we performed a threefactorial ANOVA, comprising the within-subjects factors laterality (left-right), anteriocity (anterior-posterior), and stimulus condition (low-arousal positive, neutral, and negative, and high-arousal negative), followed by planned pairwise comparisons. Positive words were contrasted with neutral words. High- and low-arousal negative words were compared with neutral words, and high- and low-arousal negative words were also contrasted.

For ERP analyses, electrodes were averaged for four regions across the critical time frame of 80 to $120 \mathrm{msec}$ : left anterior (FP1, F3, F7, FC5, T7), right anterior (FP2, F3, F8, FC6, T8), left posterior (C3, CP5, P3, P7, O1), and right posterior (C4, CP6, P4, P8, O2). Apart from the targeted early time frame of 80 to $120 \mathrm{msec}$, we explored other ERP time frames that were investigated by previous studies of affective word processing (see, e.g., Kissler, Herbert, Winkler, \& Junghofer, 2009): the time frame of 140-190 msec, the early posterior negativity $(200-250 \mathrm{msec})$, and the late positive component (450-750 msec).

For estimating the potential neural generators of the early ERP effect, sLORETA analyses (Pascual-Marqui, 2002) were conducted. The averaged ERP data of each subject and condition within the critical time frame $(80-120 \mathrm{msec})$ were submitted to the sLORETA model; thus, images of the electric neuronal activity were derived from the extracranial measurements. These estimated current source densities for each of the 6,430 voxels in MNI (Montreal Neurological Institute) space, each representing $5 \mathrm{~mm}^{3}$ of brain tissue, were time-frame-wise normalized; that is, the average activation of each time frame was normalized to a constant value. Data were baselinecorrected and $\log$ transformed. To correct for multiple comparisons, the $\alpha$ was set to $p<.005$ [two-tailed; $t(19)>3.17$ ]. Maximal $t$ values of the respective areas are reported.

\section{RESULTS}

\section{Behavioral}

In the RT analysis, there was a main effect of stimulus condition $\left[F(3,57)=15.78, p \leq .01, \eta_{\mathrm{p}}^{2}=.45\right]$. Positive words revealed significantly faster RTs than did neutral words $\left[F(1,19)=9.09, p \leq .01, \eta_{\mathrm{p}}^{2}=.32\right]$. High-arousal negative words elicited significantly faster RTs than did low-arousal negative $\left[F(1,19)=27.32, p \leq .01, \eta_{\mathrm{p}}^{2}=.59\right]$ and neutral $\left[F(1,19)=4.36, p \leq .05, \eta_{\mathrm{p}}^{2}=.19\right]$ words. Low-arousal negative words revealed slower RTs than did neutral words $\left[F(1,19)=10.73, p \leq .01, \eta_{\mathrm{p}}^{2}=.36\right]$. For means and standard errors, see Figure 1 and Table 2.

In the error analysis, there was a main effect of stimulus condition $\left[F(3,57)=8.82, p \leq .01, \eta_{\mathrm{p}}^{2}=.32\right]$. Positive words revealed significantly fewer errors than did neutral words $\left[F(1,19)=10.23, p \leq .01, \eta_{\mathrm{p}}^{2}=.35\right]$. High-arousal negative words revealed significantly less errors than did low-arousal negative words $[F(1,19)=10.55, p \leq .01$, $\left.\eta_{\mathrm{p}}^{2}=.36\right]$, but did not differ significantly from neutral words $\left[F(1,19)=2.75, p=.11, \eta_{\mathrm{p}}^{2}=.13\right]$. Low-arousal negative words only showed a nonsignificant trend to elicit more errors than did neutral words $[F(1,19)=3.23$, $\left.p=.09, \eta_{\mathrm{p}}^{2}=.15\right]$. For mean error rates and standard errors, see Figure 1 and Table 2.

ERPs. There was a significant effect of stimulus condition in the early time window of 80 to $120 \mathrm{msec}$ after the stimulus presentation started $[F(3,57)=4.39, p \leq .01$, $\left.\eta_{\mathrm{p}}^{2}=.19\right]$. Positive words revealed a significantly larger negativity than did neutral words $[F(1,19)=7.90, p \leq .01$, $\left.\eta_{\mathrm{p}}^{2}=.29\right]$. High-arousal negative words were significantly more negative than low-arousal negative $[F(1,19)=6.71$, $\left.p \leq .05, \eta_{\mathrm{p}}^{2}=.26\right]$ and neutral $[F(1,19)=4.40, p \leq .05$, $\left.\eta_{\mathrm{p}}^{2}=.19\right]$ words. Low-arousal words did not differ significantly from neutral words $(F<1)$. In all of these analyses, there were no significant interactions of frontality and/ or anteriocity with the experimental conditions (all $F \mathrm{~s} \leq$ 1.4). Only in the analysis comparing high- versus lowarousal negative words did the interaction with laterality provide a nonsignificant trend $[F(1,19)=3.38, p=.07$, $\left.\eta_{\mathrm{p}}^{2}=.16\right]$. See Figure 2 for the ERPs of exemplary electrodes. For means and standard errors, see Table 2.

Neither the time frame of 140-190 msec nor the early posterior negativity (200-250 $\mathrm{msec}$ ) provided any significant main effects or topography interactions with the experimental conditions $(F \mathrm{~s} \leq 1.5, p \mathrm{~s} \geq .22)$. The late positive component (450-750 msec) showed a significant threeway interaction of laterality, anteriocity, and experimental conditions $[F(3,57)=2.8, p \leq .05]$. Paired comparisons revealed that only high-arousal negative words provided a significantly greater positivity than neutral words in the left- and right-posterior electrode clusters $[t \mathrm{~s}(19) \geq 2.8$, $p s \leq .01]$. This in part replicates the results of previous studies, which found that high-arousal negative words elicit a greater late positivity than do neutral words (see Kissler et al., 2009; Scott et al., 2009), but this result may also be explained by the saliency of the relatively rarely occurring arousing stimuli (Donchin \& Coles, 1988).

\section{SLORETA}

Positive words did not reveal any significantly greater activation than did neutral words. High-arousal negative words elicited significantly greater activation than did low-arousal negative words in a left occipito-temporal region, including the left fusiform $(t=3.46 ; x, y, z=-46$, $-54,-17)$ and middle temporal gyri $(t=4.18 ; x, y, z=$ $-60,-50,0$; see Figure 3). Contrasting high-arousal negative words with neutral words confirmed this activation

Table 2

Means and Standard Errors for the Behavioral Measures and the Targeted Early Time Frame

\begin{tabular}{|c|c|c|c|c|c|c|c|c|c|c|c|c|}
\hline \multirow[b]{3}{*}{ Condition } & & & & & \multicolumn{8}{|c|}{ Amplitudes (80-120 msec, $\mu \mathrm{V})$} \\
\hline & \multicolumn{2}{|c|}{ RT (msec) } & \multicolumn{2}{|c|}{ Errors } & \multicolumn{2}{|c|}{$\begin{array}{c}\text { Left } \\
\text { Anterior }\end{array}$} & \multicolumn{2}{|c|}{$\begin{array}{c}\text { Right } \\
\text { Anterior }\end{array}$} & \multicolumn{2}{|c|}{$\begin{array}{c}\text { Left } \\
\text { Posterior }\end{array}$} & \multicolumn{2}{|c|}{$\begin{array}{l}\text { Right } \\
\text { Posterior }\end{array}$} \\
\hline & $M$ & $S E$ & $M$ & $S E$ & $M$ & $S E$ & $M$ & $S E$ & $M$ & $S E$ & $M$ & $S E$ \\
\hline High-arousal negative & 619 & 10 & 2.0 & 0.3 & -2.2 & 0.3 & -1.9 & 0.3 & -0.7 & 0.4 & -0.1 & 0.4 \\
\hline Low-arousal negative & 643 & 10 & 3.9 & 0.7 & -1.2 & 0.3 & -1.3 & 0.3 & -0.1 & 0.3 & 0.2 & 0.3 \\
\hline Neutral & 630 & 9 & 2.8 & 0.4 & -1.5 & 0.4 & -1.4 & 0.3 & -0.2 & 0.4 & 0.2 & 0.3 \\
\hline Positive & 617 & 9 & 1.4 & 0.4 & -2.3 & 0.4 & -2.0 & 0.3 & -0.9 & 0.4 & -0.4 & 0.3 \\
\hline
\end{tabular}



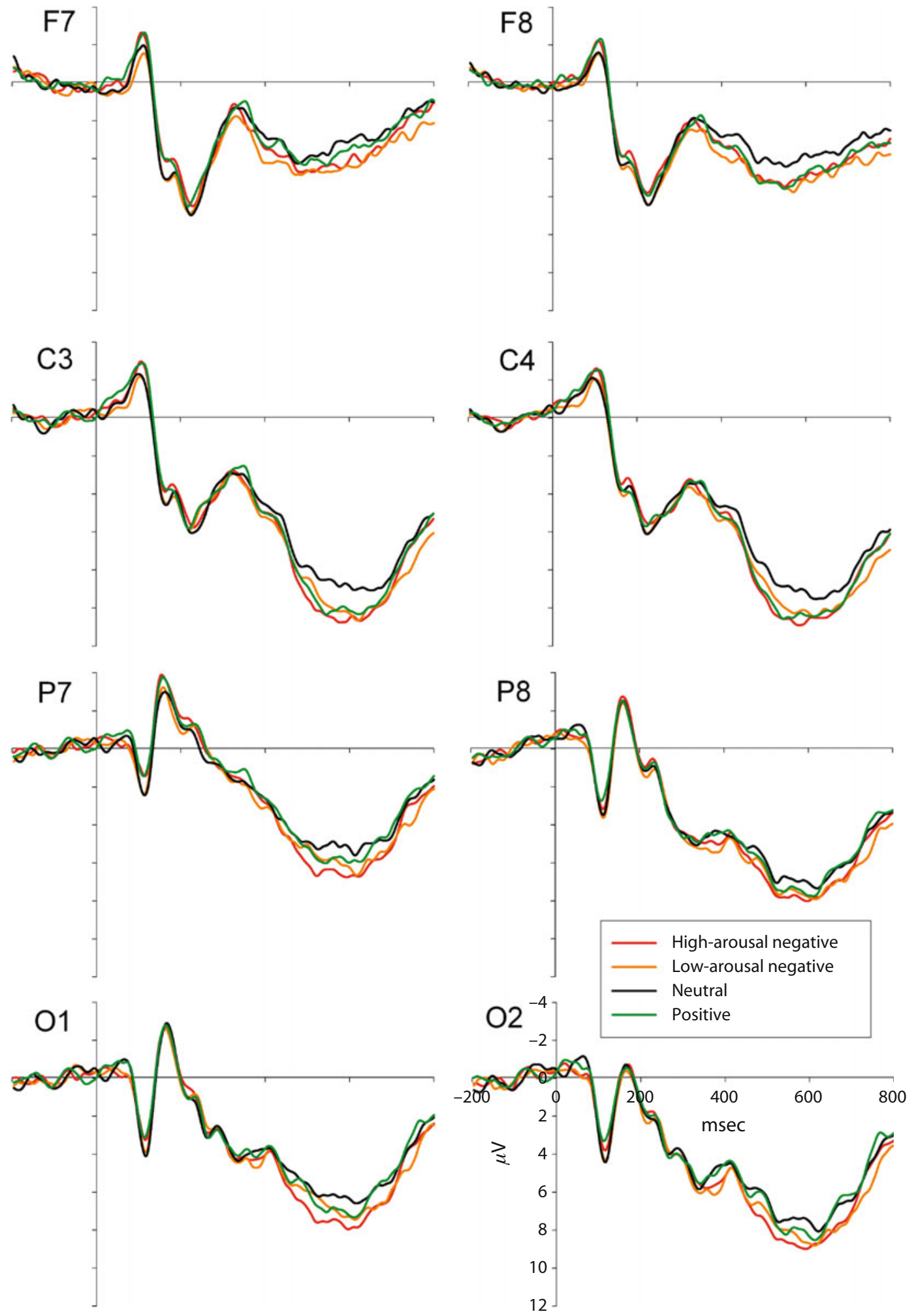

Figure 2. The event-related potentials for the four stimulus conditions at eight exemplary electrodes. 
difference (left fusiform, $t=4.45 ; x, y, z=-48,-58$, -17 ; left middle temporal gyrus, $t=4.85 ; x, y, z=-56$, $-59,-3$; see Figure 3).

\section{DISCUSSION}

Whereas the behavioral facilitation to positive words was observed regardless of their arousal level, as was reflected by faster RTs and fewer errors, arousal seems to modulate behavioral responses to negative words. Thus, differences in arousal might explain the inconsistent findings of previous studies using negative words. These studies showed a speed-up (Nakic et al., 2006; Williamson et al., 1991), no influence (Siegle et al., 2002), or even a trend toward slowing in lexical decisions (Kuchinke et al., 2005; MacKay et al., 2004). Most interestingly, another recent study (Larsen et al., 2008) mathematically disentangled the influence arousal on negative words, while canceling out the variance accounted for by various lexical variables. The authors observed longer RTs for emotionally negative words when arousal and other lexical variables were controlled for. The findings of the present study converge with this result, suggesting that emotional information can interfere with a decision that is theoretically based on cognitive information only (Siegle et al., 2002). In addition to Larsen et al.'s (2008) finding, the present study showed that high-arousal negative words elicited faster RTs and fewer errors than did neutral or low-arousal negative words. Thus, it appears that the inhibitory role of negative valence on word recognition could be overruled by an arousal mechanism, which allows for fast and less error-prone reactions.

The observed shortening of RTs for high-arousal negative words is in line with the previous studies' finding of a similar speed-up during lexical decision. Nakic et al. (2006) observed this RT decrease for highly negative but not for moderately negative words. The authors, however, did not control for arousal. Nevertheless, it is likely that the highly negative words were also of high arousal (Bradley \& Lang, 1999; Võ et al., 2009). Moreover, Thomas and LaBar (2005) showed that priming effects during lexical decision are enhanced for high-arousal taboo words as compared with neutral words, whereas low-arousal negative words showed no such enhancement of priming effects. This result has already indicated the influential role of arousal on negative words. The present study goes beyond this finding by showing that arousal also facilitates unprimed word recognition in negative words.

\section{High-Arousal - Low-Arousal Negative}
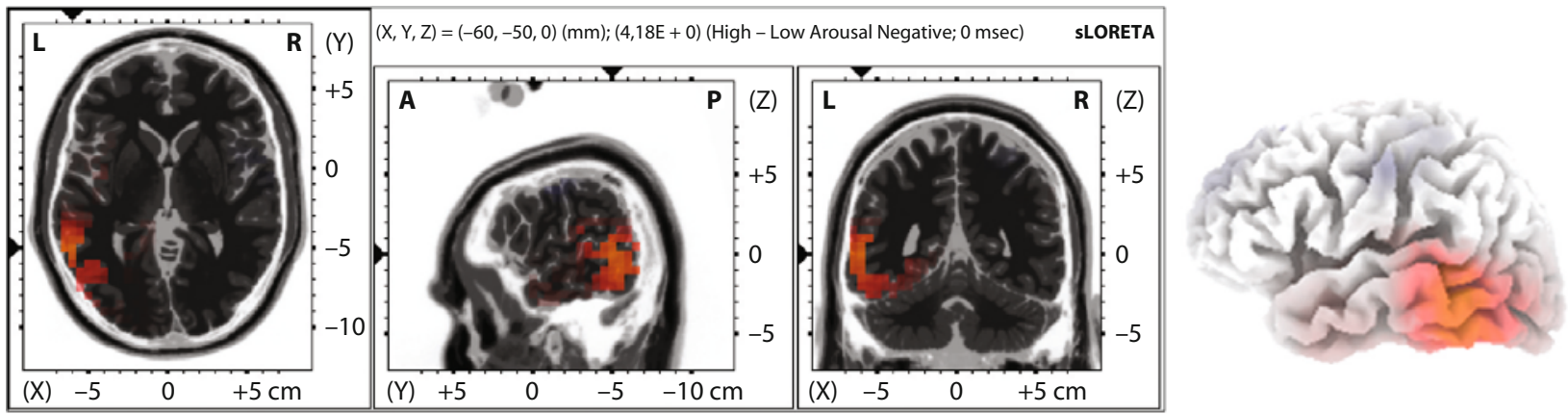

High-Arousal Negative - Neutral
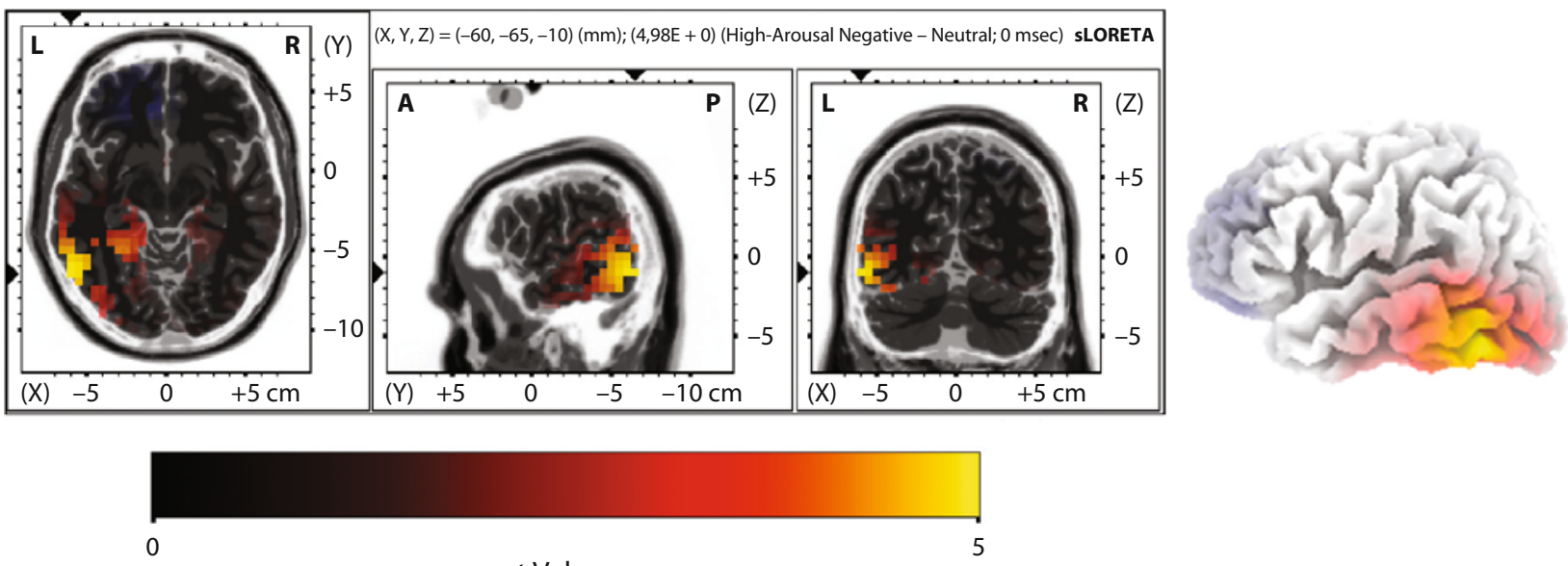

$t$ Values

Figure 3. The maximum contrasts of high- and low-arousal negative words (upper panels), and high-arousal negative and neutral words (lower panels). Significant activation differences were observed in the occipito-temporal gyrus, including the fusiform gyrus. The $X-Y-Z$ coordinates (MNI space) in the left panels show the activation maxima in the middle temporal gyrus. 
Apart from Thomas and LaBar's (2005) study, most other previous experiments taking arousal into concern manipulated arousal and emotional valence simultaneously. They presented high-arousal positive and negative words, and contrasted them with low-arousal neutral words (see Kissler et al., 2007; Scott et al., 2009). Although controlling for many influential variables in word recognition necessitated less extreme valence manipulations than in previous studies, the present study shows that positive emotional valence still exerted its facilitatory influence when arousal was controlled for. Moreover, arousal determined whether the effect of negative words was facilitatory (high-arousal negative words) or inhibitory (low-arousal negative words), in comparison with that of neutral words. This indicates that low-arousal positive and negative words are processed differently.

The experimental conditions revealing the fastest responses - that is, positive and high-arousal negative words-elicited a greater ERP negativity than did the slower responses to neutral and low-arousal negative words in the time window of 80 to $120 \mathrm{msec}$. This may be taken as evidence that the behavioral facilitation observed for low-arousal positive and high-arousal negative words stems at least partially from early effects. As such, the present results replicate and extend the findings of Scott et al. (2009), who found high-arousal negative words to elicit a greater negativity than did low-arousal neutral words in the same time frame. However, this result was obtained only for high-frequency words. In contrast, the present study found the same early ERP arousal effect using low-frequency words (see Table 1). Moreover, Scott et al. did not observe the early ERP effect in positive words. This discrepancy might be due to differences in the task and the control variables used in these studies. The participants of the present study were instructed to respond within $1 \mathrm{sec}$ after the stimulus presentation. We suggest that this time pressure may have resulted in an augmented usage of a lexical fast-guess mechanism, as implemented in the MROM (Grainger \& Jacobs, 1996), which puts an emphasis on early processing.

In addition to the control variables of length, word frequency, and valence used by Scott et al. (2009), we also controlled for imageability, number of syllables, number of orthographic neighbors, and mean type and token letter and bigram frequency (see Table 1). The application of these additional control variables may have resulted in a more consistent early processing across items, which might have increased the probability to observe early ERP effects in low-frequency positive and high-arousal negative words. In sum, our results indicate that for negative words, it is the level of arousal and not the negative valence per se that affects the early processing.

Supporting the idea that lexical access for neutral words can be underway around $100 \mathrm{msec}$ poststimulus (Sereno \& Rayner, 2003), the present data suggest that lexical access is speeded in positive and in high-arousal negative words. Thus, the time frame of the present ERP effects $(80-120 \mathrm{msec})$ might capture the initial moments of lexical access in these affective stimuli. Similar to our findings, those of Ortigue et al. (2004) showed occipi- tal source localization differences that were the result of laterally presented emotional words around $100 \mathrm{msec}$ poststimulus (see also Bernat, Bunce, \& Shevrinc, 2001). Moreover, since Scott et al.'s (2009) early effect seemed to be modulated by word frequency, and word frequency effects were argued to constitute an upper limit for the time frame of lexical access (e.g., Dambacher et al., 2006; Hauk \& Pulvermüller, 2004), the notion of an early lexical locus of the present ERP effects gains support.

This idea contrasts with Kissler et al.'s (2007) conclusion that emotional processing occurs only after lexical access. We suggest that the evolutionary advantage of emotional information processing in part results from its attribute to speed up decisions, particularly when fast decisions are important. Since no such decisions were required in Kissler et al.'s study, the earliest emotional activation might not have been strong enough to be detected in the ERPs.

Such a lexical interpretation might also imply that semantic information can be activated in this early time frame. Since emotional words seem to trigger more associations than do neutral words, much of the effects of emotional valence may be accounted for by semantic cohesion (Maratos, Allan, \& Rugg, 2000; Talmi \& Moscovitch, 2004; but see McNeely, Dywan, \& Segalowitz, 2004). Another study, suggesting a semantic, and thus lexical, locus of the present effect comes from Skrandies (1998). He found that the semantic dimensions of words affect word processing as early as $80 \mathrm{msec}$ after the stimulus presentation. Slightly later, semantically integrative effects during sentence processing have been observed (Penolazzi, Hauk, \& Pulvermüller, 2007).

The early ERP time frame showed the same increased negativity to positive and high-arousal negative words, which may suggest a similar process in both conditions. However, sLORETA could not narrow the most likely neural source for the early ERP effect to positive words, which contrasts with a left occipito-temporal region emerging as the most likely neural source for the early arousal effects for negative words. This divergence points toward the early facilitation processes for low-arousal positive and high-arousal negative words to be based on different neural mechanisms.

Within the left occipito-temporal region's showing a stronger activation to high-arousal negative than to lowarousal negative and neutral words, one subregion was the fusiform gyrus. This region was proposed to act as an interface between visual word form and higher order stimulus properties (Devlin, Jamison, Gonnerman, \& Matthews, 2006; Price \& Devlin, 2003; but see, e.g., Dehaene et al., 2002; McCandliss, Cohen, \& Dehaene, 2003). Moreover, the largest activation differences were obtained in voxels located in the left medial temporal gyrus, which has been associated with semantic processing (see Price, 2000 , for a review). We thus suggest that the co-activation of the left fusiform and the medial temporal gyrus supports Price and Devlin's (2003) suggestion of the fusiform gyrus operating as a hub mediating between visual word form and higher order stimulus properties, such as semantics. 
It is intriguing that the present ERP effect ascribed to arousal in negative words was localized in about the same brain region as was Kissler et al.'s (2007) localization of affective word processing. Their finding, however, was observed in a slightly later time frame. Like in the present study, Kissler and colleagues concluded that this effect reflects semantic processing. We propose that all of the early time frames prior to $300 \mathrm{msec}$ contribute to semanticaffective processing. This suggestion is corroborated by Hinojosa, Carretié, Valcárcel, Méndez-Bértolo, and Pozo (2009). When the task is likely to be performed without semantic information, by identifying letter strings in contrast with nonletter stimuli, none of the early time frames is sensitive to the affective features of words. However, which of the early ERP time frames are more or less sensitive to semantic processing appears to be modulated by the application of a fast-guess mechanism. Computational models of word recognition (Grainger \& Jacobs, 1996) can account for such differences in the processing dynamics by modeling differential task demands. Moreover, a computational model of affective word processing proposing that affective features take effect during an initial access to a hypothetical mental lexicon would account for the present results (Kuchinke, 2007). However, its assumption of arousal affecting positive and negative valence equally requires revision in the light of the present findings.

\section{AUTHOR NOTE}

We thank Benny Briesemeister for his help during stimulus selection, Michael Dambacher and Mario Braun for helpful comments, and Nina Blaskewitz for proofreading. This work was supported by the Deutsche Forschungsgemeinschaft (research unit "Conflicts as signals in cognitive systems," TP 3 Jacobs, JA 823/4-1) and the cluster of excellence "Languages of Emotion" at the Free University Berlin. Address correspondence to M. J. Hofmann, Department of Psychology, Free University Berlin, Habelschwerdter Allee 45, 14195 Berlin, Germany (e-mail: mhof@zedat.fu-berlin.de).

\section{REFERENCES}

Batyen, R., Piepenbrock, R., \& Gulikers, L. (1995). The CELEX Lexical Database (Release 2) [CD-ROM]. Philadelphia: University of Pennsylvania, Linguistic Data Consortium.

Bernat, E., Bunce, S., \& Shevrinc, H. (2001). Event-related brain potentials differentiate positive and negative mood adjectives during both supraliminal and subliminal visual processing. International Journal of Psychophysiology, 42, 11-34. doi:10.1016/S0167 -8760(01)00133-7

Bradley, M. M., \& Lang, P. J. (1999). Affective norms for English words (ANEW): Stimuli, instruction manual, and affective ratings (Tech. Rep. C-1). University of Florida, Gainesville, Center for Research in Psychophysiology.

Carretié, L., Hinojosa, J. A., Martín-Loeches, M., Mercado, F., \& TAPIA, M. (2004). Automatic attention to emotional stimuli: Neural correlates. Human Brain Mapping, 22, 290-299. doi:10.1002/ hbm. 2003

Dambacher, M., Kliegl, R., Hofmann, M., \& Jacobs, A. M. (2006). Frequency and predictability effects on event-related potentials during reading. Brain Research, 1084, 89-103. doi:10.1016/ j.brainres.2006.02.010

Dehaene, S., Le Clec'H, G., Poline, J., Le Bihan, D., \& Cohen, L. (2002). The visual word form area: A prelexical representation of visual words in the fusiform gyrus. NeuroReport, 13, 321. doi:10.1097/ 00001756-200203040-00015

Devlin, J. T., Jamison, H. L., Gonnerman, L. M., \& Matthews, P. M. (2006). The role of the posterior fusiform gyrus in read- ing. Journal of Cognitive Neuroscience, 18, 911-922. doi:10.1162/ jocn.2006.18.6.911

Donchin, E., \& Coles, M. G. (1988). Is the P300 component a manifestation of context updating? Behavioral \& Brain Sciences, 11, 357-427.

Geday, J., Guedde, A., Boldsen, A.-S., \& Kupersa, R. (2003). Emotional valence modulates activity in the posterior fusiform gyrus and inferior medial prefrontal cortex in social perception. NeuroImage, 18, 675-684. doi:10.1016/S1053-8119(02)00038-1

Graf, R., NAgler, M., \& JACOBS, A. M. (2005). Factor analysis of 57 variables in visual word recognition. Zeitschrift für Psychologie, 213, 205-218. doi:10.1026/0044-3409.213.4.20

Grainger, J., \& JACOBS, A. M. (1996). Orthographic processing in visual word recognition: A multiple read-out model. Psychological Review, 103, 518-565.

Hackley, S. A., \& Valle-Inclán, F. (1999). Accessory stimulus effects on response selection: Does arousal speed decision making? Journal of Cognitive Neuroscience, 11, 321-329. doi:10.1162/ 089892999563427

Hauk, O., \& Pulvermüller, F. (2004). Effects of word length and frequency on the human event-related potential. Clinical Neurophysiology, 115, 1090-1103. doi:10.1016/j.clinph.2003.12.020

Herbert, C., Junghofer, M., \& Kissler, J. (2008). Event related potentials to emotional adjectives during reading. Psychophysiology, 45, 487-498. doi:10.1111/j.1469-8986.2007.00638.x

Hinojosa, J. A., Carretié, L., Valcárcel, M. A., MéndezBértolo, C., \& Pozo, M. A. (2009). Electrophysiological differences in the processing of affective information in words and pictures. Cognitive, Affective, \& Behavioral Neuroscience, 9, 173-189. doi:10.3758/CABN.9.2.173

Hinojosa, J. A., Martín-Loeches, M., \& Rubia, F. J. (2001). Eventrelated potentials and semantics: An overview and an integrative proposal. Brain \& Language, 78, 128-139. doi:10.1006/brln.2001.2455

Hofmann, M. J., Stenneken, P., Conrad, M., \& Jacobs, A. (2007). Sublexical frequency measures for orthographic and phonological units in German. Behavior Research Methods, 39, 620-629.

Kissler, J., Herbert, C., Peyk, P., \& Junghofer, M. (2007). Buzzwords: Early cortical responses to emotional words during reading. Psychological Science, 18, 475-480. doi:10.1111/j.1467 -9280.2007.01924.x

Kissler, J., Herbert, C., Winkler, I., \& Junghofer, M. (2009). Emotion and attention in visual word processing - An ERP study. Biological Psychology, 80, 75-83. doi:10.1016/j.biopsycho.2008.03.004

KUCHINKE, L. (2007). Implicit and explicit recognition of emotionally valenced words. Unpublished doctoral dissertation, Free University Berlin.

Kuchinke, L., Jacobs, A., Grubich, C., Võ, M., Conrad, M., \& HerrmanN, M. (2005). Incidental effects of emotional valence in single word processing: An fMRI study. NeuroImage, 28, 1022-1032. doi:10.1016/j.neuroimage.2005.06.050

Kuchinke, L., Võ, M. L.-H., Hofmann, M., \& Jacobs, A. (2007). Pupillary responses during lexical decisions vary with word frequency but not emotional valence. International Journal of Psychophysiology, 65, 132-140. doi:10.1016/j.ijpsycho.2007.04.004

Larsen, R. J., Mercer, K. A., Balota, D. A., \& Strube, M. J. (2008). Not all negative words slow down lexical decision and naming speed: Importance of word arousal. Emotion, 8, 445-452. doi:10.1037/1528 $-3542.8 .4 .445$

LeDoux, J. (1996). The emotional brain. New York: Simon \& Schuster. MacKay, D., Shafto, M., Taylor, J., Marian, D., Abrams, L., \& DYER, J. (2004). Relations between emotion, memory, and attention: Evidence from taboo Stroop, lexical decision, and immediate memory tasks. Memory \& Cognition, 32, 474-488. doi:10.1080/ 01690960042000148

Maratos, E. J., Allan, K., \& RugG, M. D. (2000). Recognition memory for emotionally negative and neutral words: An ERP study. Neuropsychologia, 38, 1452-1465. doi:10.1016/S0028-3932(00)00061-0

McCandliss, B. D., Cohen, L., \& Dehaene, S. (2003). The visual word form area: Expertise for reading in the fusiform gyrus. Trends in $\mathrm{Cog}$ nitive Sciences, 7, 293-299. doi:10.1016/S1364-6613(03)00134-7

McNeely, H. E., Dywan, J., \& Segalowitz, S. J. (2004). ERP indices of emotionality and semantic cohesiveness during recognition judgments. Psychophysiology, 41, 117-129. doi:10.1111/j.1469 -8986.2003.00137.x 
Nakic, M., Smith, B., Busis, S., Vythilingam, M., \& Blair, R. (2006). The impact of affect and frequency on lexical decision: The role of the amygdala and inferior frontal cortex. NeuroImage, 31, 1752-1761. doi:10.1016/j.neuroimage.2006.02.022

Onton, J., Westerfield, M., Townsend, J., \& Makeig, S. (2006). Imaging human EEG dynamics using independent component analysis. Neuroscience \& Biobehavioral Reviews, 30, 808-822. doi:10.1016/ j.neubiorev.2006.06.007

Ortigue, S., Michel, C. M., Murray, M. M., Mohr, C., CarbonNEL, S., \& LANDIS, T. (2004). Electrical neuroimaging reveals early generator modulation to emotional words. NeuroImage, 21, 1242 1251. doi:10.1016/j.neuroimage.2003.11.007

Osgood, C. E., SucI, G. J., \& Tannenbaum, P. H. (1957). The measurement of meaning. Urbana: University of Illinois Press.

Pascual-Marqui, R. D. (2002). Standardized low-resolution brain electromagnetic tomography (sLORETA): Technical details. Methods \& Findings in Experimental \& Clinical Pharmacology, 24(Suppl. D), 5-12.

Penolazzi, B., Hauk, O., \& Pulvermüller, F. (2007). Early semantic context integration and lexical access as revealed by event-related brain potentials. Biological Psychology, 74, 374-388. doi:10.1016/ j.biopsycho.2006.09.008

Pizzagalli, D. A., Lehmann, D., Hendrick, A. M., Regard, M., Pascual-Marqui, R. D., \& Davidson, R. J. (2002). Affective judgments of faces modulate early activity $(\sim 160 \mathrm{msec})$ within the Fusiform Gyri. NeuroImage, 16, 663-677. doi:10.1111/1469-8986.00112

Price, C. J. (2000). The anatomy of language: Contributions from functional neuroimaging. Journal of Anatomy, 197, 335-359.

Price, C. J., \& Devlin, C. (2003). The myth of the visual word form area. NeuroImage, 19, 473-481. doi:10.1016/S1053-8119(03)00084-3

Scott, G. G., O'Donnell, P. J., Leuthold, H., \& Sereno, S. C. (2009). Early emotion word processing: Evidence from event- related potentials. Biological Psychology, 80, 95-104. doi:10.1016/ j.biopsycho.2008.03.010

SEReno, S. C., \& Rayner, K. (2003). Measuring word recognition in reading: Eye movements and event-related potentials. Trends in Cognitive Sciences, 7, 489-493. doi:10.1016/j.tics.2003.09.010

Siegle, G., Ingram, R., \& Matt, G. (2002). Affective interference: An explanation for negative attention biases in dysphoria? Cognitive Therapy \& Research, 26, 73-87. doi:10.1023/A:1013893705009

SKrandiES, W. (1998). Evoked potential correlates of semantic meaning-A brain mapping study. Cognitive Brain Research, 6, 173 183. doi:10.1016/S0926-6410(97)00033-5

TAlmi, D., \& Moscovitch, M. (2004). Can semantic relatedness explain the enhancement of memory for emotional words? Memory \& Cognition, 32, 742-751.

Thomas, L. A., \& LaBar, K. S. (2005). Emotional arousal enhances word repetition priming. Cognition \& Emotion, 19, 1027-1047. doi:10.1080/02699930500172440

Võ, M. L.-H., Conrad, M., Kuchinke, L., Urton, K., Hofmann, M. J., \& JACOBS, A. M. (2009). The Berlin Affective Word List Reloaded (BAWL-R). Behavior Research Methods, 41, 534-539. doi:10.3758/ BRM.41.2.534

Võ, M. L.-H., Jacobs, A. M., Kuchinke, L., Hofmann, M., ConRAD, M., Schacht, A., \& Hutzler, F. (2008). The coupling of emotion and cognition in the eye: Introducing the pupil old/new effect. $P$ sychophysiology, 45, 130-140. doi:10.1111/j.1469-8986.2007.00606.x

Williamson, S., Harpur, T., \& Hare, R. (1991). Abnormal processing of affective words by psychopaths. Psychophysiology, 28, 260-273.

WundT, W. (1896). Grundriss der Psychologie [Fundamentals of psychology]. Leipzig: Engelmann.

(Manuscript received November 11, 2008; revision accepted for publication July 31, 2009.) 